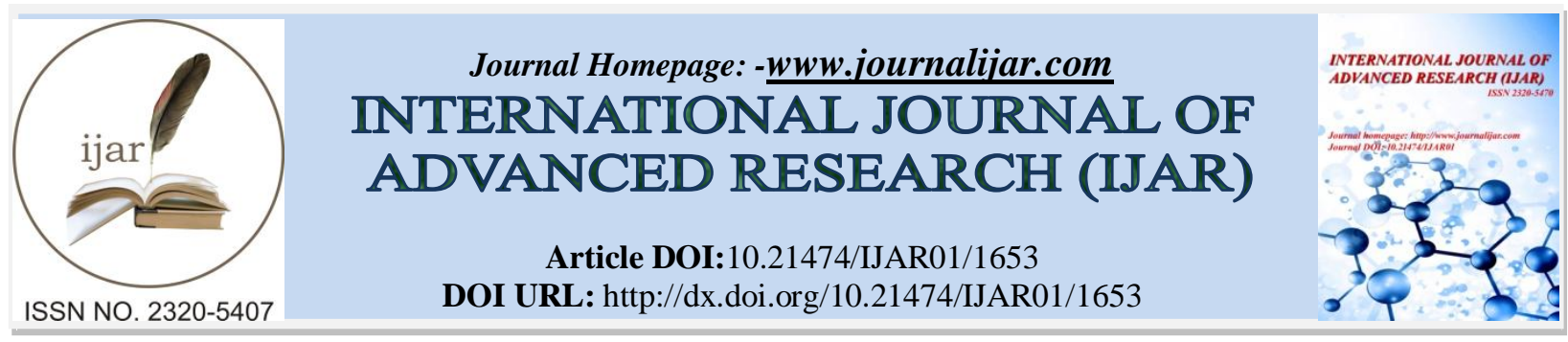

RESEARCH ARTICLE

\title{
MICROSURGERY FOR VARICOSE VEINS USING VARADY HOOK TECHNIQUE.
}

Dr. Omar Rabee Hashim Al Dahhan.

Cardiothoracic and vascular Surgeon at Fallujah teaching hospital,Iraq.

\section{Manuscript Info}

.........................

Manuscript History

Received: 12 July 2016

Final Accepted: 16 August 2016

Published: September 2016

Key words:-

Varicose vein microsurgery ,Varady

hook phlebectomy, outpatient surgery,

local anesthesia, spinal anaesthesia

\section{Abstract}

The classical high ligation and saphenous vein stripping requires hospitalization.Generalanaesthesia, long convalescence, loss of income, unacceptable scarring and possible permanent nerve injury. This report describes the technique of invaginated axial stripping in conjunction with tributary stab avulsion (Varadyhook) phlebectomy. Using femoral block anaesthesia with supplemented local infiltration or spinal anesthesia. the varicose tributaries are avulsed, through multiple stab incisions only $1.5-3 \mathrm{~mm}$ long, with specially designed hooks. This is performed in an ambulatory (office) setting, making varicose vein surgery a minimally invasive procedure. One hundred and sixty eight patients with 203 involved limbs were operated on during a two years period. Postoperative pain and complications were minimal. All patients immediately resumed normal daily activities. Cosmoses were excellent. There have been no recurrences in up to 2 years follow up. This procedure adheres to strict hemodynamic principles. Elimination of hospitalization, reduced postoperative morbidity, immediate ambulation, minimal nerve damage, excellent cosmoses and finally, obvious cost efficiency should make this form of varicose vein surgery appealing to surgeons and patients alike by making the future surgical care for varicose veins available today.

Copy Right, IJAR, 2016,. All rights reserved.

\section{Patients and methods:-}

One hundred and sixty-eight patients with primary varicose veins with a total of 203 limbs were seen in Fallujah Teaching hospital between April 2012 and December 2014. All patients were evaluated by physical examination and non-invasive continuous wave (cw) Doppler ultrasound venous studies. Of these patients $147(87.5 \%)$ were female and $21(12.5 \%)$ were male; $119(70.8 \%)$ were less than 50 years old, $49(29.2 \%)$ were 50 years or older; 133 (79.2\%) had unilateral and $35(20.8 \%)$ bilateral involvement; 95 (46.8\%) were right, and $108(53.2 \%)$ were left legs for a total of 203 involved limbs. From those $23(10 \%)$ patients needs sclerotherapy that had been done at time of surgery.

\section{Three major groups of varicosities were identified:-}

Group I. $125(61.6 \%)$ legs had varicose veins in the territorial distribution of the long saphenous vein. A saphenofemoral junctional (SFJ) escape was found in $120(59 \%)$ limbs. It was associated with concomitant saphenous trunk incompetence exhibiting various degrees of reflux in only 80 ( $39 \%)$ limbs. In 30 (15\%) limbs the main saphenous trunk was found normal and competent with varicosities limited to the medial and lateral accessory 
veins. Non- junctional escape points were detected in the remaining $52(26 \%)$ limbs.

Group II .20 (9.9\%) legs had short saphenous varicosities and saphenopopliteal junction (SPJ) incompetence was found in all of them.

Group III. 58 (28.6 \%) legs had nonsaphenous varicosities. The varicose veins were mainly limited to the lateral thigh venous system.

\section{Preoperative assessment:-}

A careful preoperative examination was mandatory in order to tailor the procedure appropriately to the hemodynamic pathology of each patient. The clinical examination alone (observation, percussion wave, Trendelenburg test, etc.) may not accurately identify all the components of the regurgitated circuit3. Therefore, a continuous wave $(\mathrm{cw})$ bidirectional Doppler ultrasound examination performed with the patient standing, is mandatory in all cases to detect venous flow, pathway of incompetence and the most proximal escape point accurately. Duplex imaging (Biosound Phase 2, Biosound, Indianapolis, IN) was only used in cases in which it was believed that the clinical and Doppler examination failed to provide the required information. It was also used for mapping the long saphenous vein in cases where stripping was contemplate. The detailed clinical and noninvasive examination protocol has been published elsewhere 2.4

\section{The Technique:-}

\section{Special instrumentation: -}

The operation is designed to be performed in an ambulatory or office setting, to cause minimal trauma, little or no convalescence, and result in maximal cosmoses. Specially devised hooks in different sizes have been introduced by different practitioners such as ( Varady )Muller. These hooks permit removal (avulsion) of varicosities via minute incisions, not longer than $1.5-3 \mathrm{~mm}$, which do not require sutures. The surgical tray should also have the 'mini strippers' introduced by Varadyphlebodissectar(s), straight and curved baby Kocher's or Halsted's to assist in grasping the veins, and regular mosquito forceps. And numbing solution that contains $500 \mathrm{ml}$ normal saline, adrenaline one ampule, lidocaine $2 \% 20 \mathrm{ml}$ and sodium bicarbonate $20 \mathrm{ml}$ all mixed and injected around the vein for easy dissection and to decrease the ecchymosis after avulsion.

\section{Preoperative marking:-}

With the patient standing in a warm room all veins are marked with a permanent marker. A successful procedure demands precise and accurate marking; therefore the operating surgeon should do it in person. The most proximal escape point is revalidated with Doppler ultra- sound and marked too. If stripping is contemplated, duplex mapping of the long saphenous vein is helpful to mark the entry sites of its tributaries precisely.

\section{Varady Hook phlebectomy:-}

Due to their superficial location, i.e. just below the skin and above the membranous fascia, tributary varicose veins are easily amenable to avulsion by hook phlebo-extraction. With an 11 blade tip held in a Kelly or a mosquito forceps, or even with an 18 or 16 gauge needle, a small 1-3 mm long stab (puncture) wound is made along the border of the previously marked varicosities, making sure that the dermis is split as well. Due to the small openings, no special effort is made to stay in the Langer's lines. Whenever possible, however, the skin incisions should be made along the longitudinal axis of the leg. The exception is the area surrounding the knee where the stab wound should be placed transversally parallel to Langer's lines.

Patients leave the office 30-45 min after the procedure.in case of regional anesthesia and after 4 hours in case of spinal anesthesia. Post-surgical discomfort is usually minimal and $1-2$ tablets of $500 \mathrm{mg}$ panadol suffice for pain control in the evening after surgery. No leave of absence from work is necessary. All patients are permitted to resume normal daily activities, including returning to work, on the same day of the surgery. Patients are permitted to resume all sporting activities as well, except heavy exercise, on the first post operative day. Showering is permitted $24 \mathrm{~h}$ after surgery with proper leg coverage. Obligatory follow-up visits are at 1week, 2-3 weeks and 2-3 months after surgery.

\section{Complications:-}

Transient neurologic complications from the loco- regional anaesthesia can occur. Motor fibers of superficial mixed nerves (femoral, peroneal) may be affected, especially when higher concentrations of anesthetic are used. After femoral block anaesthesia, the tone and strength of the ipsilateral quadriceps muscle should be checked before the 
patient is asked to stand up. Nerve palsies are invariably transient, clearing within several hours. Permanent nerve damage can occur only if a nerve is inadvertently hooked and avulsed.

Bleeding from the wound sites might occur. This is likely to manifest itself immediately following surgery when the patient stands up. As a precaution, patients are asked to walk in the office $1 \& 15$ min after surgery and are reexamined before leaving. If bleeding does occur, it can be readily controlled by additional pressure with reinforcement of the pressure dressing.

A phlebitic reaction may occur days or weeks after surgery and is due to a retained and clotted vein that was partially avulsed or missed. Incision and drainage of a fresh clot, local compression, $1200 \mathrm{mg}$ ibuprofen (Motrin) qd for 3-5 days, will resolve the symptoms.

Lymphatic accumulations (lymphocele) or fistulas, wound infection, hypertrophic scarring, have been reported.

\section{Relative contraindications:-}

Veins encased in dense fibrotic tissue or previous scar may be difficult to avulse. These include varicose veins in the gaiter or ankle area with liposclerotic skin, post sclerotherapy veins, post surgery residual veins, post phlebitic veins, as well as prepatellar and pretibial veins that may be closely attached to the fascia. In these cases, compressive sclerotherapy may be indicated.

\section{Results:-}

All 203 varicose limbs were operated on in an office setting and under loco regionalanaesthesia or spinal anesthesia as described.

106 patients ( 63\%) of patients operated under local anaesthesia or femoral regional block while 62patients (37\%) requires spinal anesthesia .

Neurologic complications were detected in three patients. In form of transient nerve palsies as a result of the locoregional anaesthesia. In one patient quadriceps palsy occurred after a femoral 3-in-1 block. All symptoms resolved within 1-2 days.

Five patients develop bleeding when they stand after operation and all of them treated by enhance pressure overdressing.

Localized superficial phlebitis occurred in 4 patients, 1-2 weeks following surgery, and presumably caused by a clotted vein segment left in situ. The reaction resolved within 5-7 days following therapy with ibuprofen (Motrin) $80 \& 1200 \mathrm{mg}$ day, compression, and continued ambulation. Seven patients had residual varicose veins which were obvious 1-2 weeks following surgery. Three patients with larger varicose segments had avulsion under local anaesthesia when they were detected. Four patients with smaller residual varicosities were treated by compressive sclerotherapy, with total obliteration.

No patient developed lymphatic collection or lymphocele. Prophylactic antibiotics were used for one day, and there were no wound infections. No deep phlebitis or pulmonary emboli was encountered. As of yet there have been no recurrent varicose veins identified.

\section{Discussion:-}

Since the beginning of the century, stripping of the long (and short) saphenous vein has been widely used in the surgical management of primary varicose veins. Keller14, Babcock and MayoI are among the early pioneers. The techniques used subsequently can be summarized by the following four steps: (a) division of the saphenous vein and ligation of the junction(s); (b) stripping (internal) of the entire saphenous vein; (c) excision and ligation of the varicose tributaries and (d) division and ligation of all incompetent perforators.

Unfortunately, the rationale for this procedure, even today, is based on the assumption that all varicose vein patients have a junctional valve escape, i.e. saphenofemoral (SFJ) or saphenopopliteal (SPJ) incompetence, and that the entire saphenous vein trunk is incompetent. This makes high ligation and routine ankle-to-groin (or to the popliteal fossa) stripping mandatory for all forms of truncal varicosities. However, the recently accumulated hemodynamic and topographic data on varicose veins clearly contradict most of these assumptionszx $4 * 10 * 1$ 
Bjordal' clearly demonstrated that haemodynamically significant distal perforator systolic (deep-tosuperficial) outflow is nonexistent in uncomplicated primary varicose veins, making the search and the wholesale ligation of perforators a futile surgical exercise in varicose vein surgery. Moreover, the distal ankle perforators connect with the posterior arch vein, which is a tributary, rather than with the infrapopliteal segment of the main saphe nous vein. Avulsion of the varicose tributaries in the calf will, therefore, automatically disconnect any outflowing distal perforator. Additionally, the infrapopliteal segment nerve injury to the long saphenous or sural nerve. Of the saphenous vein, in many instances, was not The selective high ligation and invaginated axial stripfound to be involved in the varicealprocesses.

his relatively new topographic and haemodynamic data, coupled with the quests for maximal preservation of the main saphenous trunk as possible vascular graft material, make the classical routine and blind ankle-to- groin stripping 'overkill'. The limited groin-to-knee stripping that we usually perform is haemodynamically satisfactory in most forms of primary varicose disease". The detailed haemodynamic principles of surgical care for primary varicose veins have been the subject of previous communications2 4 19.

The principles of stab avulsion were independently introduced by Muller20,21 and Rivlin9. Muller coined the term 'phlebectomieambulatoire' or ambulatory phlebecomy and Rivlin named the procedure 'multiple cosmetic phlebectomy'. Both used small existing or makeshift instruments to grab and avulse the varicosities through small skin openings. While Muller was the first to intro- duce his modified crochet hooks that facilitated the removal of the varicosities through even smaller (I .5-3 mm) incisions, it was Rivlin, in 1975, who reported an excellent 10 year recurrence rate of $7 \%$ in 1993 operated varicose limbs. Oesch22, 23 ('mini-incision phlebectomy') and Varady24z25 ('micro-surgical varicectomy or phlebextraction'), designed different hooks. Large26x27in 1985 coined the term 'stab avulsion venectomy'. Thus the 'ambulatory stab avulsion phlebectomy' is a combination of already existing terminology that seems to us to correctly reflect the true character of the procedure.

In the face of recently published evidence that sclerotherapy, in any of its forms, is not a definitive therapeutic alternative for truncal varicose veins due to the high recurrence rates2R-3', surgery remains the treatment of choice for primary varicose veins. The invaginated form of stripping in conjunction with tributary stab avulsion (hook) phlebextraction does not necessitate any haemodynamic compromise. On the contrary, it is a haemodynamically correct procedure, provided the preoperative examination is judiciously executed. Using loco-regional (femoral 3-in1 block) anaesthesia and performed in an ambulatory (office) setting, the method has placed varicose vein surgery in the realms of minimally-invasive procedures.

Elimination of hospitalization, reduced postoperative morbidity, immediate ambulation, lack of nerve damage, excellent cosmoses and finally, obvious cost efficiency should make this unique form of varicose vein surgery appealing to surgeons and patients alike.

\section{Summary:-}

The treatment of varicose vein become much easier and having better results and cost effective with the use of Varady hook technique especially cosmetically speaking. In comparison with old traditional blind ligation and stripping that was associated with longer hospitalization, general anesthesia, longconvalescence, loss of income, unacceptable scars and sural nerve injury.

The selective hook method sounds haemodynamically sound procedure as accurate Doppler mapping always precedes it. Postoperative pain is minimal. Convalescence is short and rapidly patients restore their daily activities. It is cost effective with excellent cosmoses. From above it is highly recommended for hook surgery to replace traditional varicose stripping. 


\section{References:-}

1. Bjordal R. Flow and pressure studies in venous insufficiency.ActaChir Stand (Suppl) 1988; 544: 30-3

2. Goren G, Yellin AE. Ambulatory stab evulsion phlebectomy for truncal varicose veins. Am J Surg 1991; 162: 16674

3. Tibbs DJ, Fletcher EWL.Direction of flow in superficial veins as a guide to venous disorders in lower limbs. Surgery 1983; 93: 758-67

4. Goren G, Yellin AE. Primary varicose veins: topographic and haemodynamic correlations. J CurdiovascSurg 1990; 31: 671-7

5. Winnie AP, Ramamurthy S, Durrani Z. The inguinal paravascular technique of lumbalanaesthesia: the ' 3 -in-l' block. AnesthAnalg 1973; 52: 889-96

6. Taylor EW, Fielding JW, Keighley MR, Alexander- Williams J. Long saphenous vein stripping under local anesthesia. Ann R CONSurgEngl 1981; 63: 2067

7. Charlton JE.Long saphenous vein stripping under local anaesthesia. Ann R Co11Surg Engl 1981; 63: 363-4

8. Rivlin S. Recurrent varicose veins. Med J Aust 1966; 1: 1097-102 Rivlin S. The surgical cure of primary varicose veins. Br J Surg 1975; 62: 913-17

9. Koyano K, Sakaguchi S. Selective stripping operation based on Doppler ultrasonic findings for primary varicose veins of the lower extremities. Surgery 1988; 103: 615-19

10. Negus D. Should the incompetent saphenous vein be stripped to the ankle? Phlebology1986; 1: 33-6

11. Conrad P. Groin-to-knee downward stripping of the long saphenous vein. PhIebologJ: 1992; 7: 20-2

12. Staelens I, van der Stricht J. Complication rate of long tripping of the greater saphenous vein. Phlebologv 1992; 7: $67-70$

13. Keller WL.A new method of extirpating the internal saphenous and similar veins in varicose conditions; a preliminary report. NY Med J 1905; 82: 385

14. Babcock WW.A new operation for the extirpation of varicose veins of the leg. NY Med J 1907; 86: 1536 Mayo CH. Treatment of varicose veins. SurgGynecObst 1906; 2: 385-8

15. Large J. Doppler testing as an important conservation measure in the treatment of varicose veins.Aust NZ J Surg 1984; 54: 357-9

16. MacFarlane R, Godwin RJ, Barabas AP. Are varicose veins and coronary artery bypass surgery compatible? Lancet 1985; 2: 859

17. Goren G. Primary varicose veins: hemodynamic principles of surgical care. The case for the ambulatory stab evulsion technique. VASA 1991; 20: 365-8

18. Muller R. Traitement des varices par la phlebectomieambulatoire. Bull Sot FrPhleb 1966; 19: 277-9 (in French)

19. Muller R. La phlebectomieambulatoire.Phlebology 1978; 31: 273-8 (in French)

20. Oesch A. Formen und moderneTherapie der Varikosis.Schweiz Med Wschr 1988; 118: $1242-7$ (in German)

21. Oesch A. Indikationen und Ergebnisse der ambulanten Varizentherapie. TherapeutischeUmschau 1991; 48: 6926 (in German)

22. Varady Z. Die MikrochirurgischePhlebextraction. Vusomed Aktuell1990; 3: 23-5 (in German)

23. Varady Z. Moglichkeiten der Varizenoperation.Angio 1986; 8: 385-9 (in German)

24. Large J. Surgical treatment of saphenous varices, with preservation of the main great saphenous trunk. J VuscSurg 1985; 2: 88691

25. Large J.The stab avulsion technique for removing varicose veins.Surg Rounds 1985; 8(2): 91-100

26. Goren G. Injection sclerotherapy for varicose veins: history and effectiveness. Phlebology 1991; 6: 7-1 1

27. Bishop CCR, Fronek HS, Fronek A, Dile RB, Bernstein EF.Real-time color duplex scanning after sclerotherapy of the greater saphenous vein. J Vast Surg 1991; 14: 505-8

28. Gongolo A, Giraldi E, Buttazzoni L, Spreafico G, Pinzani A, Ravasini R, Pavei P. 11sistema duplex nel follow up dellaterapiasclerosantedella vena grandesafena. Radio1 Med 1991; 81: 303-8 (in Italian)

29. Einarsson E, Eklof B, Neglen P. Schlerotherapy or surgery as treatment for varicose veins: A prospective randomized study. Phlebology 1993; 8: 22-6 